\title{
Burocracia, criatividade e discernimento: lições de uma cafeteira desaparecida
}

DOI

http://dx.doi.org/10.11606/ 1678-9857.ra.2020.178185

\section{Ciméa Barbato Bevilaqua}

Universidade Federal do Paraná | Curitiba, PR, Brasil

cimea@ufpr.br|https://orcid.org/0000-0002-6886-0395

Com base na descrição do processo administrativo instaurado a partir do sumiço de uma cafeteira em um órgão público federal, proponho que a transposição ponderada e criativa da distância entre o esquematismo das fórmulas burocráticas e a complexidade das situações às quais elas se dirigem é tão constitutiva da burocracia quanto suas expressões mais insensatas, que frequentemente resultam em violência e injustiça. De um lado, as prescrições normativas conferem ao processo um impulso próprio, que prenuncia sanções aos servidores formalmente responsáveis pelo bem. De outro, e ao mesmo tempo, sua tramitação desencadeia um investimento cuidadoso para conter um movimento cego em direção a resultados indesejáveis. Essas condições interpelam a consideração usual da discricionariedade no serviço público - que chamarei de discernimento, conforme certo uso nativo - como expressão de arbítrio individual. Em vez disso, realçam o caráter intrinsecamente coletivo do discernimento burocrático, indispensável para a efetivação consequente das normas.

Bureaucracy, creativity and discernment: lessons from a missing coffee maker
Antropologia da burocracia, processos administrativos, servidores públicos, discricionariedade, discernimento

\section{KEYWORDS}

Anthropology of bureaucracy, administrative proceedings, civil servants, discretion, discernment 


\section{BUROCRACIA, CRIATIVIDADE E DISCERNIMENTO: LIÇÕES DE UMA CAFETEIRA DESAPARECIDA ${ }^{1}$}

No início do artigo intitulado "Dead zones of imagination: on violence, bureaucracy and interpretive labor" (2012), David Graeber descreve o emaranhado de exigências burocráticas em que se viu enredado quando sua mãe foi vítima de uma sucessão de acidentes vasculares que, poucas semanas depois, a levariam à morte. Para pleitear atendimento pelo programa público de saúde norte-americano, era preciso comprovar que o patrimônio da requerente se enquadrava em certo limite. Entretanto, esse patamar seria rapidamente ultrapassado caso não fosse possível movimentar a conta bancária na qual sua aposentadoria era depositada. Para ter acesso à conta era preciso uma procuração, que dependia de várias autorizações e do preenchimento de um longo formulário. O banco, porém, recusou esses documentos: não só o formulário a ser preenchido era outro, como faltava a assinatura da titular da conta. Toda a documentação foi refeita e assinada - com dificuldade, em virtude do quadro clínico da paciente-e novamente recusada pelo banco: o beneficiário da procuração havia assinado no campo destinado ao preenchimento do seu nome por extenso, e preenchido seu nome no campo reservado à assinatura.

Ao final do relato, Graeber observa que as burocracias parecem se constituir de forma que boa parte das pessoas não seja capaz de cumprir suas exigências. $E$ comenta, com certa perplexidade, que o aspecto pessoalmente mais perturbador nessa experiência foi perceber que lidar com formulários tinha feito com que ele próprio se tornasse estúpido: "Como pude não perceber que estava preenchendo meu nome na linha 'assinatura', embora estivesse investindo tanta energia mental e emocional naquela situação?" (: 108). Uma parte da resposta estaria na direção a que essa energia se voltou: o esforço para compreender e influenciar as pessoas que detinham algum poder burocrático sobre ele o teria tornado menos inclinado a perceber quando elas Ihe diziam para fazer algo estúpido. (No caso, o lugar onde supostamente deveria assinar havia sido indicado a ele pela tabeliã.) Um segundo motivo de perplexidade, segundo Graeber, era a escassa atenção dispensada pela antropologia aos procedimentos burocráticos ou, mais diretamente, à "patente circularidade e vacuidade, para não dizer imbecilidade, da burocracia". Com raras exceções, a literatura antropológica teria tomado a direção oposta: em vez de indagar por que a burocracia produz absurdo, teria se ocupado em explicar "por que tantas pessoas acreditam que é assim" (: 109).

O principal exemplo seria o livro clássico de Michael Herzfeld, The social production of indifference, no qual o autor sugere que "as raízes simbólicas da burocracia ocidental não devem ser buscadas, em primeiro lugar, nos formulários oficiais da própria burocracia, [mas] sobretudo nas reações populares à burocracia - nos modos como pessoas comuns efetivamente lidam com e conceptualizam as relações
1 | Dedico este artigo, com admiração, aos meus colegas de burocracia Osvanir José Andrade e Carlos Alberto Balhana (in memoriam). 
burocráticas" (Herzfeld, 1992: 3 e 8, citado por Graeber, 2012: 110). Embora ressalve que Herzfeld e outros autores não deixaram de notar que a imersão em códigos e regulamentos burocráticos leva as pessoas a agir de formas que, em outros contextos, "seriam consideradas idiotas", Graeber acrescenta com ironia que as análises acadêmicas tendem a desconsiderar como explicação legítima a verdade que qualquer um sabe por experiência própria (idem).

O foco do próprio Graeber no restante do artigo - uma versão pouco modificada da Malinowski Memorial Lecture apresentada em 2006 na London School of Economics - não está de fato na burocracia, mas na relação entre a violência estrutural e as formas de esquematização típicas das categorias e procedimentos burocráticos, assim como da própria teoria social. Mas se naquele momento ainda era possível creditar ao caráter fastidioso de documentos e formulários a alegada falta de interesse dos antropólogos pela burocracia ("paperwork is boring"), os anos subsequentes registraram uma notável proliferação de etnografias atentas às práticas burocráticas.

Uma parte desses trabalhos, ao abordar o universo estatal a partir da perspectiva daqueles que buscam obter documentos e serviços públicos, ou são destinatários (frequentemente involuntários) de políticas governamentais, enfatiza a indiferença, o autoritarismo, a violência e a arbitrariedade da burocracia e/ou de seus agentes (Herzfeld, 1992; Scott, 1998; Cupta, 2012; Fassin, 2015). Sem negligenciar a relevância desses estudos, menos ainda a realidade dos efeitos que descrevem, interessa-me aqui atentar ao que se passa nos "mundos internos" (Mathur, 2017) de instituições estatais - como aliás tem feito uma leva de trabalhos recentes dedicados às atividades cotidianas de servidores públicos, à produção e circulação de documentos e à condução de processos administrativos e judiciais.

A partir dessa perspectiva, o percurso analítico que proponho é inverso, mas em certa medida complementar, ao delineado por Graeber. Em vez de chamar a atenção para as iniquidades produzidas (ou sustentadas) pelo curso mais ou menos automático de procedimentos burocráticos anódinos, ou manifestamente absurdos, busco descrever como esses resultados são-ao menos em certas circunstâncias - diligentemente evitados no cumprimento de normas e atribuições burocráticas.

No artigo de Graeber, a capacidade da burocracia (sem dúvida real) de "fazer com que pessoas inteligentes ajam de forma flagrantemente estúpida" (2012: 105), experimentada pessoalmente em circunstâncias bastante penosas, conduziu à exploração analítica das "zonas mortas da imaginação". Meu ponto de partida é uma situação banal, na qual estive indiretamente envolvida: o sumiço de uma cafeteira elétrica do departamento onde trabalho em uma universidade pública. O fato deu origem a um processo administrativo que se prolongou por cerca de seis anos e que, aos olhos dos próprios servidores nele implicados, revestia-se da bizarrice usualmente associada aos procedimentos burocráticos. 
Uma atenção mais cuidadosa à tramitação desse processo, porém, permite vislumbrar outra dimensão (não menos real) das práticas burocráticas: o caráter intrinsecamente criativo de ações que mobilizam, de forma coletiva, recursos intelectuais, técnicos e afetivos para conter a autonomização insensata (e potencialmente violenta) de prescrições formais. Ao argumentar que, sem isso, a efetivação consequente de normas legais e institucionais não seria possível, não pretendo simplesmente reafirmar que servidores públicos dispõem de algum grau de discricionariedade (discretion) no desempenho de suas atribuições, como tem sido reconhecido desde o estudo pioneiro de Lipsky ([1980] 2010) sobre a "burocracia de nível de rua". Meu propósito é problematizar etnograficamente a consideração usual da discricionariedade - que chamarei aqui de discernimento, aproximando-me de certo uso nativo do termo - como expressão de autonomia, arbítrio ou inclinação individual.

Com esse escopo, o texto se organiza da seguinte forma. Inicialmente, uma breve consideração da produção antropológica recente sobre práticas burocráticas, bem como de características constitutivas de processos administrativos, contribui para delinear um percurso analítico. Nas duas seções seguintes descrevo a tramitação do processo instaurado a partir do desaparecimento da cafeteira e as operações que tornaram possível alcançar certo resultado. Com base nessa experiência, busco na seção final expandir a reflexão sobre o discernimento no serviço público, em contraste com outras abordagens da discricionariedade em universos burocráticos.

\section{ARTEFATOS BUROCRÁTICOS: O PROCESSO ADMINISTRATIVO}

Em novembro de 2017 o verbete "burocracia" passou a constar, possivelmente pela primeira vez, em uma enciclopédia de antropologia (Mathur, 2017)², quando já se avolumavam as coletâneas, dossiês temáticos e os primeiros balanços de uma produção etnográfica emergente voltada às atividades cotidianas em universos burocráticos e às suas expressões mais características: documentos, arquivos e processos (Bernstein \& Mertz, 2011; Muzzopappa \& Villalta, 2011; Hull, 2012; Nakassis et al, 2013; Bierschenk \& Olivier de Sardan, 2014; Bear \& Mathur, 2015; Ferreira \& Nadai, 2015; Hoag \& Hull, 2017). Se a rubrica "antropologia da burocracia" não inaugura, de fato, um novo campo de investigação, certamente indica sua expansão e amadurecimento (Heyman, 2012), assim como mudanças de perspectiva em relação às décadas anteriores.

Como é sabido, a reflexão antropológica acerca do Estado ganhou impulso a partir da década de 1990 com o afastamento das perspectivas normativas e da retórica essencializante oriunda tanto do próprio universo estatal como da teoria social. A crítica à reificação do Estado como um ente unitário e coerente, contudo, também ensejou alguns impasses para a abordagem etnográfica de suas formas concretas de efetivação. São recorrentes nesse período os trabalhos que descrevem

$2 \mid$ A inclusão do verbete "burocracia" na Cambridge Encyclopedia of Anthropology contrasta com a escassa presença do termo em enciclopédias da área publicadas nas três últimas décadas. A título de exemplo, a palavra burocracia aparece uma única vez na Companion Encyclopedia of Anthropology (Ingold, 1994). Em duas edições consultadas da Routledge Encyclopedia of Social and Cultural Anthropology, o termo surge apenas de passagem em diferentes entradas (Barnard \& Spencer, $1996 \mathrm{e}$ 2010). Já The Social Science Encyclopedia inicialmente inclui o verbete "burocracia" na área de Sociologia e, mais tarde, na área de Relações Industriais e Administração (Kuper \& Kuper, 1996 e 2004) 
- ou denunciam - o Estado como fetiche, mito, fantasia ou ilusão (Taussig, 1993; Gupta, [1995] 2006; Hansen \& Stepputat, 2001; Aretxaga, 2003). Um corolário implícito nessas designações é a separação entre formas de ação (reconhecidas como heterogêneas e, muitas vezes, contraditórias) e formas de representação (nas quais o Estado apareceria enganosamente como um todo homogêneo, a despeito de sua fragmentação concreta). ${ }^{3}$ Uma alternativa a esse dualismo foi buscada por muitos pesquisadores na reflexão foucaultiana sobre a governamentalidade e o biopoder (Foucault, [1978] 1998). A rotinização dessa perspectiva, entretanto, também redundou frequentemente no esvaziamento da complexidade etnográfica. ${ }^{4}$

Em diálogo com desdobramentos teórico-metodológicos mais amplos da disciplina, a interrogação sobre a natureza do Estado, assim como o foco nas "narrativas produzidas pelo Estado ou sobre o Estado" (Hoag \& Hull, 2017: 4) deram lugar, a partir de meados dos anos 2000, ao interesse etnográfico pelas práticas de servidores públicos e pelas qualidades materiais da burocracia. ${ }^{5}$ Documentos e outras formas burocráticas deixaram de ser considerados simplesmente como instrumentos para fins institucionais ou como veículos de informações, discursos e representações independentes de suas condições materiais para serem reconhecidos como práticas de conhecimento que constituem as próprias organizações, suas normas, procedimentos e efeitos (Riles, 2006; Mathews, 2008; Hoag, 2011; Hull, 2012; Pinker, 2015). Interessam-me aqui, em particular, os processos administrativos como via de acesso ao mundo vivido da burocracia, bem menos "cinzento e sem vida do que parece quando visto de fora" (Bernstein \& Metz, 2011: 7).

Em linhas muito gerais, o processo administrativo é um conjunto de documentos relativos a determinada questão, organizado sob a forma de dossiê e identificado por um número de registro que indica sua posição cronológica em relação a outros conjuntos similares. É esse caráter de conjunto que, inicialmente, distingue o processo administrativo de outros papeis (cada vez mais em formato eletrônico ${ }^{6}$ ) que povoam órgãos oficiais, como memorandos e ofícios, que são também numerados, mas circulam de modo independente e estão sujeitos a normas menos estritas que aquelas que determinam a organização formal e as condições de movimentação de um processo. No que se refere a este último aspecto, todo processo possui, por assim dizer, um ciclo de vida7: uma vez iniciado, deve seguir em movimento até que o percurso pelas instâncias decisórias prescritas tenha sido cumprido. Qualquer que seja o resultado, todo processo precisa ser conclusivo: não pode deixar em aberto a questão de que trata. Por essa razão, o ciclo de vida de um processo administrativo pode ser mais ou menos longo. Contudo, está sempre sujeito a determinações legais e formais que independem de seu tema específico.

Os processos administrativos podem ter origem de duas maneiras: a partir de "fora", isto é, pela solicitação a um órgão oficial de um serviço, documento ou outras providências, encaminhada por uma pessoa, organização privada ou outra
3| Em alguns casos, essa divisão assume contornos programáticos, como nas recomendações de Hansen \& Stepputat (2001: 7-8) para a consideração analítica, por um lado, de "linguagens práticas de governo" e, por outro, de "linguagens simbólicas de autoridade". De forma análoga, Sharma \& Cupta (2006: 5) identificam as "práticas cotidianas" e as "representações" como duas vertentes distintas $d$ estudo antropológico do estado, o que os obriga a postular, num segundo momento, uma relação "dialética" entre os dois polos (2006: 19).

4 | Como observou Jonathan Spencer, realidades muito diversas passaram a ser apresentadas como "mais um exemplo do script familiar do biopoder e da resistência" (2007: 111). No período mais recente, a expansão das etnografias que tematizam práticas estatais alimentou o diálogo crítico com proposições foucaultianas e a desconfiança em relação a sua transposição automática a situações heterogêneas, da qual resultaria "um mundo muito previsível" (idem) no âmbito das análises, mas nem sempre compatível com os próprios mundos descritos, especialmente não europeus (Das \& Poole, 2004: 30; Mitchell, [1999] 2006: 179).

$\mathbf{5}$ | Foge aos objetivos deste artigo um mapeamento mais circunstanciado dess produção. Além de outras referências já citadas, uma excelente discussão da literatura em língua inglesa pode ser consultada em Hoag \& Hull (2017). Em dossiê recente, Hahonou \& Martin (2019) propõem discutir questões metodológicas suscitadas pelas pesquisa em universos burocráticos. No Brasil, um primeiro mapeamento dessa área de pesquisa foi efetuado por Teixeira e Souza Lima (2010). Dois dossiês recentes reunindo estudos que abordam a administração pública e práticas de documentação foram organizados por Souza Lima (2012) e

Ferreira e Nadai (2015).

6| Em contraponto, ver Seller \& Harper (2002).

$7 \mid$ Com essa expressão, não pretendo me referir às discussões na área de 
instituição pública; ou a partir de "dentro", isto é, por iniciativa de alguma instância do próprio órgão em questão, para o cumprimento de dever legal ou atribuição institucional. Em qualquer caso, o documento inaugural (requerimento, ofício, formulário), acompanhado ou não de outros, só adquire o caráter de processo ao ser protocolado na instância oficial a que se dirige ou onde tem origem. Por meio desse procedimento, recebe um número de registro e é acondicionado numa pasta específica, identificada por uma etiqueta que contém informações sucintas sobre a parte interessada, o assunto, a data e o local em que o processo foi iniciado. Mesmo processos eletrônicos, que nos últimos anos substituíram quase integralmente os dossiês físicos, mantêm em linhas gerais o mesmo formato.

A partir daí o processo está apto a circular, obedecendo a (pelo menos) dois conjuntos de normas: aquelas que definem sua organização formal e as condições de sua tramitação; e dispositivos legais e/ou outros regulamentos aplicáveis ao seu tema específico. Observados esses limites normativos, os processos existem para circular: o movimento é a condição por excelência da vida de um processo. Não por acaso, a capa do processo (ou o índice eletrônico dos arquivos que o compõem) costuma reservar um espaço específico para que sejam registrados todos os passos de sua tramitação. Em cada seção administrativa por onde o processo passa, o(a) funcionário(a) que o recebe deve registrar a data de recebimento e o nome da seção (caso essas informações não sejam preenchidas automaticamente pelo sistema eletrônico), apondo sua assinatura. O mesmo procedimento se repete no encaminhamento à seção seguinte. Em síntese, cada item no interior do processo deve ser identificado e ordenado segundo prescrições específicas cujo descumprimento pode conduzir à invalidação daquele item ou do próprio processo.

Em cada passo da tramitação, novos elementos são acrescentados - textos, assinaturas e carimbos, físicos ou eletrônicos -, o que faz de todo processo administrativo um empreendimento coletivo ${ }^{8}$ que associa, no transcurso de certo lapso temporal, pessoas, coisas e lugares, concretos e institucionais. No entanto, nenhum novo item pode ser acrescentado senão ao final do conjunto preexistente, cujos elementos são organizados sequencialmente e identificados com o carimbo, rubrica ou autenticação eletrônica de quem os acrescentou. Da mesma forma, nenhum item, depois de incorporado ao processo, pode ser suprimido, ${ }^{9}$ o que exige prudência e rigor de todos os que interferem em sua constituição e andamento.

Outro aspecto fundamental é que cada nova manifestação acrescentada ao processo - despacho, ${ }^{10}$ parecer ou decisão - deve levar em conta tão somente aquilo que já fazia parte dele, a menos que outras diligências (e a incorporação de seus resultados) sejam atribuição institucional daquela instância específica. De certo modo, portanto, embora sempre aberto a novos acréscimos, o processo é ao mesmo tempo um conjunto fechado que contém, num sentido muito literal, os "fatos" aos quais as intervenções de diferentes unidades administrativas dizem respeito. arquivologia (e administração) sobre o ciclo de vida dos documentos e, em algumas vertentes, suas "três idades": nascimento, vida produtiva e morte (Brasil, 2005).

$8 \mid$ De forma análoga, o

caráter coletivo de processos e decisões judiciais é sublinhado por Lewandowski (2017) em sua excelente etnografia sobre o "fazer processo" no Supremo Tribunal Federal.

9| A anulação de algum item pode ser efetuada, excepcionalmente, por meio de um documento posterior que o torne sem efeito. Esse procedimento não exclui fisicamente do processo o item anulado. No entanto, sua presença deve ser considerada a partir de então como uma ausência isto é, não pode incidir no desenvolvimento do processo.

10| Toda manifestação de uma instância administrativa pela qual o processo tenha passado pode ser considerada um "despacho". Dependendo do caso, pode conter alguma providência ou decisão, ou simplesmente indicar a movimentação do processo para a instância seguinte. 
Constituído pela circulação, um processo não pode jamais ficar à deriva. Dessa forma, uma das características mais fundamentais de um processo é que cada seção administrativa, ao se manifestar e acrescentar novos elementos ao conjunto, deve também remetê-lo à seguinte. Esse caminho é em geral predeterminado por normas que estabelecem as instâncias pelas quais o processo deve passar e em que ordem. Por exemplo, certas seções devem necessariamente se manifestar sobre determinado assunto para que uma decisão seja tomada; ou, tratando-se de recurso à decisão de uma autoridade administrativa, o processo caminha sempre da instância inferior à superior.

Conforme a natureza da questão tratada e das próprias intervenções feitas em etapas anteriores, porém, esse caminho pode comportar desvios ou variações, isto é, o processo pode passar por instâncias cuja manifestação não era formalmente prescrita ou ir e vir entre unidades administrativas e níveis hierárquicos. Da mesma forma, como nem sempre existe norma específica que determine um prazo máximo para cada etapa de tramitação, também pode ocorrer que o processo fique retido em determinada instância por vários meses e até anos. Essa aparente estagnação não significa, porém, que o processo tenha deixado de tramitar: a ausência de movimento, como se verá adiante, também pode ser um modo de movimentação.

Se a possibilidade de trilharcaminhos não prescritos, ou de permanecer imóvel por um intervalo mais ou menos longo, confere algum grau de imponderabilidade ao processo administrativo, isto só pode ocorrer dentro de limites formais e normativos cuja elasticidade é sempre restrita. Em cada etapa, a direção e o propósito da passagem à unidade seguinte, quando ela ocorre, devem ser formalmente explicitados por meio de expressões como: "à seção ... para análise e parecer"; "à seção ... para conhecimento e providências". Essas formas padronizadas de encaminhamento evidenciam que, a cada passo, as manifestações não se dirigem à parte interessada no processo - que, em geral, só toma conhecimento de seu conteúdo quando todos os procedimentos foram concluídos -, mas às instâncias administrativas imediatamente anterior e posterior.

Quando todas as etapas prescritas foram cumpridas, o processo esgota seu potencial de movimento e seu ciclo de vida: é encerrado e encaminhado ao arquivo (físico ou eletrônico), destino final de todo processo administrativo. Mas se todo processo deve ter um fim, sua conclusão nem sempre significa que a questão que Ihe deu origem obteve uma solução concreta. $O$ arquivamento indica apenas que se tornou possível encerrar a tramitação à luz das normas e regulamentos pertinentes. Dito de outro modo, a questão foi efetivamente "resolvida", mas no âmbito do próprio processo que a contém. Por isso mesmo, uma vez arquivado, o processo não volta à vida (excepcionalmente, um processo concluído pode adquirir uma segunda vida, mas como parte de um novo processo e para a discussão de questões distintas). A decisão de arquivamento é definitiva e, se tudo ocorreu da forma prescrita, indisputável ${ }^{11}$.
11 | Esta qualidade é compartilhada com os processos judiciais. Como assinala Latour (2004), 0 procedimento de qualificação característico do processo judicial (em contraste com as cadeias de referência da ciência) traça um caminho irreversível, justamente porque deve chegar a uma decisão. Se o que a decisão final enuncia deve ser tomado como verdade, não se trata de uma verdade referencial: ela diz respeito tão somente à exaustão dos mecanismos existentes de apelação. 
Esses atributos gerais do processo administrativo - seu caráter circunscrito e, uma vez concluído, definitivo - reafirmam a necessidade de renunciar a uma abordagem que se concentre no conteúdo proposicional dos elementos que o compõem ou do próprio conjunto que os articula. Em primeiro lugar, como a descrição anterior evidencia, suas qualidades formais são constitutivas daquilo que enunciam (e vice-versa), de modo que a própria distinção entre um e outro aspecto se torna imprópria. Não menos importante, esses artefatos burocráticos, como proponho chamá-los, caracterizam-se justamente pelo esvaziamento deliberado, obtido por procedimentos minuciosos, da conexão entre os elementos que os constituem e um mundo exterior àquele ao qual tais artefatos pertencem. Nesse sentido, abordá-los a partir de seu possível caráter referencial é impedir-se de compreendê-los, como têm demonstrado já há algum tempo as análises sobre práticas de documentação (Peirano, 2002; Riles, 2006; Pinto, 2007; Hull, 2012): os artefatos burocráticos se referem fundamentalmente uns aos outros, isto é, constituem seu próprio contexto e significam, antes de tudo, no interior do próprio universo burocrático.

Da mesma forma, o desfecho de um processo administrativo não advém da conexão com um domínio exterior a ele mesmo, mas das conexões estabelecidas entre o conjunto limitado de informação factual existente em seu próprio âmbito e o conjunto, igualmente finito, das disposições legais que regulamentam o assunto em pauta e das normas que determinam sua tramitação. Levando em conta, contudo, que os caminhos percorridos jamais são os únicos possíveis e produzem efeitos díspares para além do universo circunscrito do próprio processo, é necessário compreender como esses caminhos e efeitos são concretamente produzidos em situações específicas. E isto implica considerar não apenas as qualidades formais dos processos administrativos, mas também as formas de engajamento intelectual e afetivo que suscitam.

É hora, portanto, de retornar à cafeteira elétrica desaparecida e ao processo administrativo correspondente, um pequeno dossiê de vinte páginas arquivado há quase quinze anos na Pró-Reitoria de Cestão de Pessoas da Universidade Federal do Paraná. Em que pese o longo tempo transcorrido, suas qualidades ambivalentes - reconhecidamente descabido, mas potencialmente perigoso - permanecem na memória dos poucos servidores da época ainda na ativa, que não se opuseram ao relato desse caso que provocou "tanta dor de cabeça".12

\section{O CASO DA CAFETEIRA DESAPARECIDA}

Aorigem do processo remonta a um ofício da chefe do Departamento de Antropologia à sua superiora hierárquica, a diretora do Setor de Ciências Humanas,,$^{13}$ comunicando o "desaparecimento de uma cafeteira elétrica marca (...), número de patrimônio (...), das dependências do departamento, aproximadamente às $11 \mathrm{~h} 15 \mathrm{~min}$ do dia
12 | Trata-se do Processo $n^{\circ}$ 23075.28890/99-31, iniciado em agosto de 1999 e concluído em junho de 2005. Embora o caso tenha se originado em meu departamento e eu o tenha acompanhado indiretamente, assim como os demais colegas, só tive acesso ao processo físico quando ele já estava em via de ser concluído. Isto ocorreu por intermédio do então diretor do Setor de Ciências Humanas, que autorizou que eu fizesse uma cópia dos autos tendo em vista meu interesse etnográfico no caso. Apresentei uma primeira reflexão a respeito do processo na VII Reunião de Antropologia do Mercosul, em 2007, mas optei por não publicá-la à época por suas eventuais implicações para um caso recém-concluído. Passado muito tempo, retomo-a agora sob nova forma e incorporando novas questões analíticas.

13 Na época denominado Setor de Ciências Humanas, Letras e Artes. No organograma da Universidade Federal do Paraná, setores são unidades acadêmico-administrativas que congregam departamentos e cursos de graduação e pós-graduação de áreas afins. Correspondem, grosso modo, às faculdades ou institutos de outras instituições federais

de educação superior 
13/07/1999". O mesmo documento descrevia as primeiras medidas tomadas - comunicação à segurança do prédio e contato telefônico com a instância superior - e solicitava "orientação para as providências necessárias". Conforme o carimbo aplicado no canto superior direito da página, o ofício foi recebido no mesmo dia pela chefe da Divisão de Apoio Administrativo da direção do Setor. ${ }^{14}$

O processo propriamente dito foi formalizado quinze dias depois, contendo, além do ofício original, uma portaria emitida pela diretora designando uma comissão de sindicância para apurar a ocorrência. A realização de sindicância é dever de ofício da autoridade em casos dessa natureza. A instauração do processo, portanto, não poderia deixar de ocorrer.

As duas folhas seguintes trazem o relatório da comissão, que ouviu as três pessoas presentes quando foi constatada a falta da cafeteira: a chefe do departamento, o secretário e um estagiário. De acordo com os depoimentos colhidos, os servidores "vasculharam o andar à procura da cafeteira" e tomaram as demais providências relatadas no ofício encaminhado à diretora. Todos foram unânimes em afirmar que a disposição física dos ambientes de trabalho não propiciava a visão do corredor e da copa (onde estava instalada a cafeteira), o que dificultava o controle da circulação de pessoas naquelas dependências. A comissão concluiu que "todas as providências no sentido de se achar a cafeteira ou de interceptar o possível ladrão foram tomadas". E, a fim de evitar a repetição de situações similares, recomendou a realização de uma "reforma na parte frontal da secretaria do departamento, para maior visibilidade, controle e segurança" (fls. 3-4, 09/08/1999).

$\mathrm{O}$ processo foi enviado à diretora que, em breve despacho manuscrito no verso da última folha do relatório, ${ }^{15}$ remeteu-o na mesma data à Pró-Reitoria de Recursos Humanos. ${ }^{16}$ Este encaminhamento, porém, deixava de cumprir um passo obrigatório em casos dessa natureza: a avaliação da Procuradoria Jurídica sobre os procedimentos e conclusões da sindicância, sem o que o processo não poderia ser concluído e arquivado. Atenta às normas legais e à polidez burocrática, a Gerência de Procedimentos Disciplinares da pró-reitoria não enviou o processo diretamente à procuradoria. Em vez disso, optou por devolvê-lo à direção do Setor com essa "sugestão" de encaminhamento.
14 | No vocabulário institucional da UFPR, a instância administrativa máxima de um Setor é designada como

"direção". Embora o termo diretoria seja mais usual em outras instituições, adoto aqui o uso local.
Figura 1:A capa do processo, com o registro das instâncias por onde passou.
15 | Esta é uma técnica burocrática praticamente desaparecida com a crescente substituição de processos em papel por eletrônicos. No início dos anos 2000, porém ainda era comum utilizar 0 verso de um ofício ou outro documento para respondêlo ou encaminhá-lo a outra unidade. A partir de uma linha imaginária dividindo a folha ao meio, na vertical, os despachos manuscritos eram feitos em sequência a partir do canto superior esquerdo. Preenchida a coluna da esquerda, as manifestações podiam eventualmente prosseguir na coluna da direita (ver figura 2). No processo aqui descrito despachos manuscritos se alternam com outros digitados em novas folhas, sempre com timbre oficial. Em qualquer caso, as manifestações são sempre seguidas da assinatura e carimbo (indicando o número de matrícula e o cargo) da pessoa responsável.

16| Atual Pró-Reitoria de Cestão de Pessoas. 
Assim foi feito, para o cumprimento do que se afigurava como uma mera formalidade. ${ }^{17} \mathrm{O}$ parecer jurídico emitido dez dias depois, contudo, apontou a existência de outras lacunas que impediam o arquivamento do processo, a começar pela ausência de comunicação à Polícia Federal, obrigatória em casos que envolvem bens patrimoniais da União. A procuradora responsável pelo parecer considerou ainda que, tendo sido confirmado o desaparecimento do bem, mas sem a determinação do culpado, caberia responsabilizar a chefia e/ou o servidor encarregado de sua guarda:

\footnotetext{
[...] sendo a instituição órgão público, não pode nem deve arcar com prejuízo patrimonial ocasionado por negligência de seus prepostos, devendo, pois, ser ressarcido pelo servidor diretamente responsável, por meio das providências administrativas a serem desencadeadas em um Processo Disciplinar, por culpa in vigilando. Assim, o que não pode ocorrer é um arquivamento antes da solução do que ocorrreu com o patrimônio e seu ressarcimento a nossa instituição (fl. 8, 27/08/1999).
}

Com a reviravolta produzida pelo parecer jurídico, o processo retornou à direção do Setor de Ciências Humanas, que o encaminhou ao departamento "para conhecimento e providência". Poucos dias depois, o processo foi devolvido à direção com o acréscimo de um arrazoado de duas páginas, aprovado por unanimidade em reunião plenária, do qual destaco a seguinte passagem:

\footnotetext{
Este Departamento não pode aceitar, a qualquer título, que a cafeteira deva ser ressarcida pelo servidor diretamente responsável (a Chefe e/ou o secretário), ou que seja desencadeado um Processo Disciplinar contra esses servidores, cujo zelo pelo patrimônio público ficou amplamente constatado nos esforços que empregaram para dar ciência à instância administrativa superior, para dar cumprimento às suas recomendações e para facilitar o trabalho da Comissão de Sindicância (fls. 10-11, 04/10/1999).
}

A manifestação não aludia unicamente ao parecer jurídico. Também reafirmava que as providências subsequentes ao sumiço da cafeteira haviam seguido orientações da instância superior, que deixara de alertar sobre a necessidade de comunicação à Polícia Federal. Não menos importante, a ausência de culpa ou negligência dos servidores do departamento havia sido atestada pela comissão de sindicância, cujo relatório fora aprovado pela diretora. Em resumo, o departamento sublinhava as responsabilidades compartilhadas pelas duas instâncias e, ao fazê-lo, requeria "o adequado desfecho deste lamentável episódio".

O documento produziu seus efeitos: em contraste com o ritmo acelerado das primeiras etapas, a partir daí o processo permaneceu estagnado por dois anos e meio, isto é, até as vésperas do encerramento do mandato da então diretora. ${ }^{18}$ Não há registro formal nos autos da saída do processo do Setor de Ciências Humanas. Em vez disso, encontra-se
17| Esta percepção estava implícita no despacho da Cerente de Procedimentos Disciplinares, que já sugeria os passos seguintes à análise jurídica: encaminhamento ao Departamento de Serviços Gerais "para fins de registro e baixa [do bem]" e, em seguida, retorno à Pró-Reitoria de Recursos Humanos "para registro no programa PAD [procedimentos administrativos disciplinares]", isto é, para que ficasse atestado que a aplicação de sanções havia sido

afastada pelo relatório da comissão de sindicância e (esperava-se) pelo parecer da Procuradoria Jurídica.
18| A direção do Setor é um cargo eletivo com mandato de quatro anos. 
no verso do documento oriundo do Departamento de Antropologia um despacho manuscrito da diretora da Divisão de Patrimônio da Pró-Reitoria de Administração devolvendo o processo ao Setor "para manifestação" (fl. 11, verso, 11/04/02).

A intervenção não era fortuita. Quaisquer que sejam as circunstâncias, a tramitação de um processo não comporta lacunas: toda passagem de uma instância a outra deve ser formalmente registrada e acompanhada de indicações precisas sobre o destino e 0 objetivo da movimentação. No caso em questão, o que parece ter ocorrido é que a diretora cujo mandato se encerrava, vendo-se obrigada a recolocar o processo em circulação, mas sem atinar com uma alternativa que atendesse simultaneamente aos compromissos com o Departamento e às recomendações da Procuradoria Jurídica, optou por silenciar, encaminhando-o (fisicamente) ao destino seguinte com a sugestão implícita de cancelamento do registro patrimonial da cafeteira e arquivamento do processo. A Divisão de Patrimônio, contudo, não se dispôs a assumir o ônus de tomar uma providência não solicitada formalmente e que ignorava o parecer jurídico presente nos autos poucas páginas antes, ainda que o sumiço da cafeteira já tivesse completado três anos.

A hesitação da diretora ao receber novamente o processo permaneceu registrada nos autos. Inicialmente ela escreveu a mão, também no verso da folha: "Ciente. De acordo com a plenária departamental" - datou e assinou (fl. 11, verso, 19 de abril 2002). Logo em seguida parece ter se dado conta de que isto não bastava. Se não era possível determinar o arquivamento do processo sem se expor, ela mesma, a procedimentos disciplinares, era preciso recolocá-lo em movimento. Em novo despacho, logo abaixo do anterior, determinou que ele fosse encaminhado mais uma vez à Divisão de Patrimônio - que, evidentemente, não queria recebê-lo, mas não podia se recusar a isso nem empregar novamente a alternativa de devolvê-lo à origem. Remeteu-o então ao seu superior hierárquico (o diretor do Departamento de Serviços Cerais), que fez o mesmo: encaminhou o processo ao seu próprio superior (o Pró-Reitor de Administração), com a sugestão de que este o enviasse novamente para análise da Procuradoria Jurídica. Depois de um longo período sem circular, o processo agora se deslocava num ímpeto equivalente à estagnação anterior: nada de substantivo era acrescentado, não se produzia nenhuma decisão.

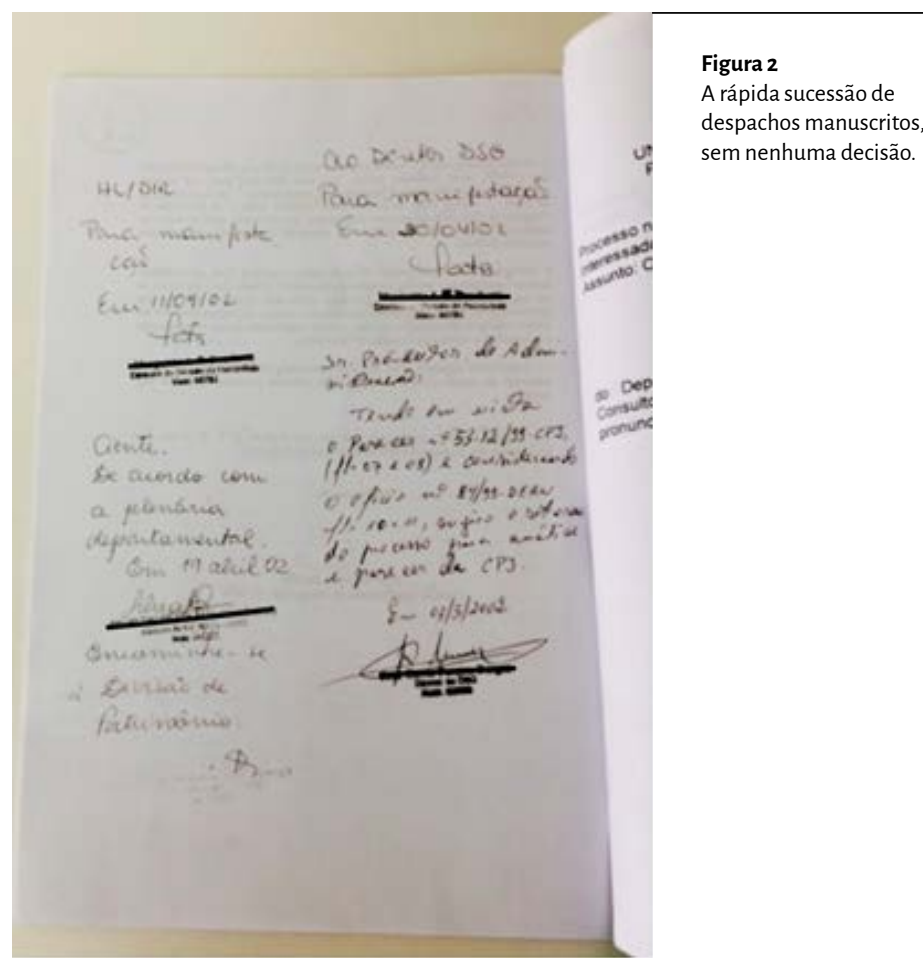


Essa velocidade improdutiva perdeu impulso com o retorno do processo à Procuradoria Jurídica. Dez meses se passaram sem que nada acontecesse, até que os autos foram devolvidos à instância anterior com um pedido de informação sobre eventuais providências tomadas junto à Polícia Federal (fl. 13, 07/03/03). O pedido e a resposta exprimem a peculiaridade das expressões burocráticas. O responsável pelo Departamento de Serviços Gerais da Pró-Reitoria de Administração, que recebeu e devolveu o processo por intermédio de seu superior, afirmou em seu despacho que "não consta nos autos" que a Polícia Federal tenha sido acionada. Obviamente, a mesma constatação já havia sido feita pela própria procuradoria. Tratava-se, porém, de registrar formalmente no processo a ausência de comunicação ao órgão policial.

Esse pequeno passo foi seguido por novo período de paralisia. Somente dezesseis meses depois a procuradora encarregada da reanálise do processo registrou que, tendo em vista o intervalo transcorrido desde o sumiço da cafeteira - que já completava cinco anos -, tornara-se "despiciendo" informar a polícia. Não obstante, não havia como reconsiderar o primeiro parecer, "posto que correto" (fl. 15, 02/09/04). Outros oito meses se passaram até que a chefe da Procuradoria Jurídica se manifestou, com um carimbo-padrão, "de acordo" com esse entendimento, que implicava a responsabilização dos servidores do Departamento de Antropologia (fl. 15, 25/04/05). O processo seguiu então para a Pró-Reitoria de Recursos Humanos, que o destinou à Gerência de Procedimentos Disciplinares, onde ele já havia estado vários anos antes. Esta, no entanto, não deu andamento a suas atribuições, isto é, à responsabilização disciplinar e pecuniária dos servidores do Departamento de Antropologia. Em vez disso, devolveu o processo à instância superior, com a sugestão de que fosse enviado mais uma vez à direção do Setor de Ciências Humanas "para conhecimento e providências cabíveis".

Desta vez, as providências ocorreram. Poucos dias depois de recebero processo, o novo diretor do Setor (que havia sucedido a ocupante do cargo quando o caso teve início) registrou nos autos que: a) a reforma das dependências do Departamento de Antropologia, sugerida pela Comissão de Sindicância, fora realizada; e b) os servidores do departamento haviam adquirido com recursos próprios uma cafeteira similar à desaparecida. Por não subsistir prejuízo patrimonial à instituição, o procedimento disciplinar havia perdido seu objeto: o caso poderia ser encerrado e arquivado - 0 que de fato ocorreu em junho de 2005, seis anos depois de seu início.

\section{CONTER A RACIONALIDADE INSENSATA, CONECTAR EXIGÊNCIAS DÍSPARES}

O longo e tortuoso percurso do processo da cafeteira desaparecida parece inversamente proporcional à sua importância intrínseca. Para levar adiante a reflexão proposta neste artigo, destaco alguns aspectos. 
1. O domínio factual, no âmbito do processo, é limitado e deixa de ser questionado tão logo a comissão de sindicância atesta que: a) a cafeteira desapareceu; e b) o culpado é desconhecido. A partir deste ponto, trata-se sobretudo de qualificar o ocorrido à luz das prescrições legais e institucionais. Formalmente, o horizonte passa a ser o próprio processo, cuja conclusão depende do cumprimento das disposições decorrentes desse enquadramento.

2. Em todas as etapas do percurso, evidencia-se a preocupação dos diferentes atores com a coerência interna (não podem existir lacunas) e com a adequação normativa (é preciso cumprir as prescrições pertinentes e registrar o seu cumprimento). Enquanto isto não ocorre, o processo deve permanecer em movimento. Não menos importante, sempre que a movimentação deixa de cumprir algum requisito formal, a instância seguinte atua para corrigir o curso tomado indevidamente.

3. Ao trilhar o caminho prescrito, o processo se encaminha, à revelia dos envolvidos em sua tramitação, para a abertura de um procedimento disciplinar contra servidores do Departamento. Todos (ou quase todos) ${ }^{19}$ parecem concordar que o prejuízo patrimonial é irrelevante e que não há culpados pelo sumiço da cafeteira, de modo que seria injusto responsabilizar os servidores e macular seu histórico funcional. Note-se ainda que, de acordo com o registro patrimonial anexado ao final do processo, a cafeteira já tinha onze anos de uso quando desapareceu.

4. Foram necessários seis anos para a conclusão e arquivamento do processo, ao longo dos quais a abertura de procedimento disciplinar foi cuidadosamente evitada. Nesse intervalo, longos períodos de estagnação se alternam com momentos de movimentação intensa, com resultados equivalentes: engavetar o processo ou fazê-lo circular de modo errático entre as mesmas instâncias, sem nenhum encaminhamento substantivo, é a mesma coisa.

A partir desses pontos é possível sugerir, de um lado, que o caso reafirma o alto grau de autonomia dos artefatos burocráticos e de suas regras próprias de constituição. É no âmbito circunscrito e autorreferenciado do processo que a articulação adequada entre um conjunto restrito de informação factual e o conjunto das normas institucionais e legais adquire um momentum próprio. De outro lado, porém, a tramitação do processo desencadeia simultaneamente um investimento cuidadoso de todos os envolvidos para conter essa autonomização e a tendência, dela decorrente, de um movimento cego em direção a resultados considerados indesejáveis. É justamente o descompasso entre a dinâmica própria do processo e a avaliação implícita de seus efeitos que permite compreender a duração, a abrangência e os ritmos de sua tramitação. Se no plano do processo é imprescindível atestar que não há prejuízo patrimonial à instituição - e em nenhum ponto há questionamento
19| Embora a etnografia não possa determinar as intenções subjetivas dos envolvidos, a única avaliação discordante parece ser a da autora do primeiro parecer jurídico sobre o caso. Note-se que, no retorno do processo à Procuradoria, há longos intervalos entre o recebimento dos autos, a reanálise do caso e a aprovação do novo parecer pela chefe do órgão. Se a avaliação não mudou, é possível supor que isso se deveu à própria presença no processo do parecer original que estabelecia limites para a argumentação posterior. 
quanto a isso -, também parece certo que, fora dele, a punição dos servidores pelo sumiço da cafeteira é percebida como desproporcional e injusta.

Outras informações etnográficas fazem sobressair ainda mais a conexão laboriosa e complexa mas, como se pode entrever, sempre necessária, entre essas duas dimensões. Se o que é coerente e razoável dentro do processo parece irracional e bizarro fora dele, não é possível deixar que ele siga seu próprio impulso. É preciso fazer com que ele enuncie algo aceitável em seus próprios termos e, ao mesmo tempo, no mundo exterior a ele. Como se verá a seguir, o encerramento do caso dependeu de elementos que não poderiam figurar de modo explícito nos autos, mas que permitiram atender ao mesmo tempo a essas duas ordens de consideração.

Em primeiro lugar, embora a aquisição de uma nova cafeteira tenha possibilitado o arquivamento do processo, ela ocorreu de modo independente da sua tramitação, poucos meses depois do sumiço da primeira e por iniciativa de um professor que sequer estava presente na ocasião. Assumindo a forma de um ato de generosidade com os colegas, a compra da nova cafeteira permitiu reiterar, no âmbito do departamento, a convicção de que os dois servidores apontados no processo como potencialmente responsáveis não deveriam arcar com o ônus do sumiço do equipamento. Formalizar a substituição da cafeteira no âmbito do processo, porém, seria equivalente a uma confissão de culpa.

Essa alternativa, considerada indigna, permaneceu fora de questão ao longo dos anos seguintes, até o surgimento de um novo fato, também independente do processo. Por determinação legal, todo bem pertencente a um órgão público é registrado sob a guarda de um servidor específico, que por ele passa a responder oficialmente. Embora ninguém tenha se dado conta disso na época, a cafeteira desaparecida não estava registrada em nome da então chefe do departamento ou do secretário, mas da professora que ocupava a chefia quando o utensílio foi adquirido. A informação somente veio à tona quando esta professora teve seu pedido de aposentadoria obstado em função da pendência relativa à cafeteira. O encontro inesperado entre os dois processos, que passaram a incidir um sobre o outro, coincidiu aproximadamente com o retorno do processo da cafeteira desaparecida à direção do Setor de Ciências Humanas, depois de dois anos parado na Procuradoria Jurídica.

Somente nessas novas circunstâncias, e após um lapso de tempo suficiente para amenizar as implicações morais e afetivas do caso, tornou-se possível o despacho do diretor do Setor atestando a substituição da cafeteira - e, a partir disso, a conclusão do processo. Já não se tratava de uma admissão de culpa: ao contrário, nas novas circunstâncias, manter a posição anterior seria impor um prejuízo direto a uma colega. Registre-se ainda que a reforma do Departamento também não decorreu das sugestões da Comissão de Sindicância, mas de necessidades de espaço surgidas durante o período de tramitação do processo e da obtenção circunstancial dos recursos necessários. 
Para todos os efeitos formais, porém, as sugestões da Comissão de Sindicância haviam sido atendidas e o prejuízo patrimonial fora finalmente reparado, em conformidade com as normas legais e com as recomendações da Procuradoria Jurídica. Se todos os demais elementos permaneceram à margem dos autos, parece claro que o caso só foi concluído quando foi possível reconectar o mundo do processo e o seu exterior de um modo compatível com as exigências específicas de cada uma dessas dimensões.

\section{CONSIDERAÇÕES FINAIS: DISCRICIONARIEDADE E DISCERNIMENTO}

O caso da cafeteira desaparecida oferece sustentação empírica à ideia de que os artefatos burocráticas são pautados por disposições imanentes ao domínio específico ao qual pertencem e, por isso mesmo, podem se tornar opacos (se não absurdos) quando confrontados com outras dimensões da experiência em relação às quais tendem a se autonomizar. Por que consumir os esforços de tantas pessoas, durante tanto tempo, para atestar o ressarcimento de um prejuízo patrimonial existente apenas no âmbito do próprio processo administrativo, uma vez que uma cafeteira elétrica com onze anos de uso poderia a justo título ser descartada como inservível? Somente quando se admite a relativa independência dos artefatos burocráticos, resultante do esvaziamento de um vínculo referencial com o que está aquém ou além deles, torna-se possível apreender a racionalidade de casos como esse. O valor heurístico dessa distinção inicial entre interior e exterior, entretanto, reside precisamente na possibilidade de, num segundo momento, compreender melhor a interconexão entre os domínios que foram analiticamente separados.

Um dos resultados mais consistentes da expansão recente das etnografias realizadas em universos estatais tem sido demonstrar que o funcionamento concreto da burocracia está longe de corresponder ao automatismo mecânico sugerido pela metáfora usual da "máquina do Estado" (Mathur, 2017: 4) ou pela caracterização weberiana do burocrata profissional como "uma engrenagem num mecanismo sempre em movimento, que lhe determina um caminho fixo" (Weber, [1946] 1982: 265). Conforme diferentes estudos evidenciam, "burocratas reais, em burocracias reais, assim como quaisquer pessoas em todo tipo de ambiente, constantemente tomam decisões, interagem com outras pessoas e ultrapassam seus próprios controles" (Bernstein e Mertz, 2011: 7). No entanto, não deixa de ser simultaneamente verdadeiro que os procedimentos burocráticos envolvem um al to grau de esquematização e estão sempre sujeitos aos paradoxos da autorreferência.

O caso aqui descrito não apenas nos relembra que a burocracia é feita de pessoas (Herzfeld, 1992: 157; Lea, 2012:110), mas que essas pessoas sabem perfeitamente que a tramitação de um processo administrativo pode produzir efeitos que, embora congruentes com as regras e procedimentos do âmbito burocrático, são irracionais e indesejáveis fora dele. Por isso mesmo, é arriscado permitir que um processo caminhe 
de modo automático. Se não é possível controlar inteiramente seu curso e seus efeitos, é preciso ao menos tentar evitar que eles sejam "flagrantemente estúpidos".

Meu argumento é que a transposição ponderada e criativa da distância entre o esquematismo das fórmulas e a complexidade das situações às quais elas se dirigem é tão constitutiva da burocracia quanto suas expressões mais bizarras, cuja insensatez anedótica frequentemente resulta em violência e injustiça. Como se viu, o processo da cafeteira desaparecida só foi concluído quando se tornou possível atender simultaneamente a exigências normativas, morais e afetivas, ainda que para isso tenha sido preciso percorrer caminhos tortuosos, alternando longas esperas com passos velozes e aparentemente vazios.

Por certo seria possível enquadrar o caso simplesmente como mais um exemplo de corporativismo ${ }^{20}$ no serviço público. Entretanto, também é possível sugerir que essa alternativa seria análoga, no plano analítico, às práticas burocráticas circunscritas à "aplicação de modelos simples e fórmulas preexistentes a situações complexas e frequentemente ambíguas" (Graeber, 2012:119). Implicaria negligenciar a sutileza das operações que, com o concurso de diferentes atores, situados em diferentes âmbitos institucionais, contribuíram para conter os impulsos de autonomização do processo sem deixar deatenderintegralmenteàs exigências legais e aos procedimentos formais.

Para além desse caso específico, o cumprimento reflexivo de leis, regulamentos e atribuições formais pode se tornar, ele mesmo, uma prescrição. Este é, por exemplo, um dos tópicos do curso à distância sobre "Ética e Serviço Público" oferecido regularmente pela Escola Nacional de Administração Pública. ${ }^{21}$ De acordo com o texto de apresentação do curso, que conta com a participação de cerca de dois mil servidores federais a cada edição, "o pressuposto dessa iniciativa é que a excelência do exercício profissional é garantida não apenas pela competência técnica, mas também pelo estímulo ao discernimento moral" (ENAP, 2014, Módulo 1: 5).

Nas lições seguintes, a noção de discernimento alude, em linhas gerais, à capacidade do servidor público de identificar, no exercício de suas tarefas cotidianas, as alternativas de ação mais capazes de obedecer ao imperativo da legalidade sem perder de vista a promoção da justiça e de fins coletivos. Em contraste com o "cumprimento objetivo das tarefas [...] segundo regras calculáveis e sem relação com pessoas" (Weber, [1946] 1982: 250), o discernimento surge como um antídoto indispensável ao automatismo das práticas burocráticas:

É claro que [...] sempre é necessário aperfeiçoar as instituições e aplicar bem as leis vigentes, mas não se pode negar que o aprimoramento do discernimento ético do servidor público tem grande papel na melhoria do serviço público em nosso país (ENAP, 2014, Módulo 1: 17).22

Embora os responsáveis pela elaboração desse material certamente não tivessem em mente uma situação tão prosaica como o sumiço de uma cafeteira
20| Uso o termo aqui em sentido corrente, sem me referir a desdobramentos específicos do debate acadêmico em torno do conceito de corporativismo Para uma discussão mais detalhada de abordagens clássicas e emergentes, ver Viscardi (2018).

21 Como parte de uma pesquisa voltada a iniciativas de formação de servidores e uniformização do serviço público, participei da edição de março de 2016, cujo material didático remontava a anos anteriores. Em minha última consulta ao sítio eletrônico da ENAP (enap.gov.br), em maio de 2020, estavam abertas as inscrições para mais uma oferta desse curso. A programação visual das apostilas tinha sido renovada, mas o conteúdo do curso permanecia o mesmo em linhas gerais.

22 | Registro, de passagem o uso aparentemente intercambiável no materia do curso de "discernimento moral" (cf. citação anterior) e "discernimento ético". Embora não seja possível aprofundar aqui essa discussão, cabe notar que a (im)possibilidade ou (in) conveniência de uma distinção estrita entre moral e ética tem sido objeto de debates na literatura antropológica recente. Para uma discussão sobre os diferentes usos e definições desses termos, ver Keane (2016) 
elétrica, não parece impróprio caracterizar o caso aqui descrito como um exemplo de discernimento nas práticas burocráticas. É preciso assinalar, contudo, uma diferença fundamental.

No material didático do curso da ENAP, o discernimento é concebido como uma disposição individual a ser aperfeiçoada pela autorreflexão de cada servidor - que as leituras e exercícios propostos buscam estimular - a respeito de seu modo de agir em seu cotidiano de trabalho. Ao menos até certo ponto, esta perspectiva se avizinha de análises acadêmicas que abordam os "dilemas do indivíduo nos serviços públicos", conforme anuncia o subtítulo do estudo clássico do cientista político norte-americano Michael Lipsky ([1980] 2010) sobre a discricionariedade na "burocracia de nível de rua". Aliás, a edição comemorativa dos trinta anos de sua primeira publicação foi traduzida para o português em 2019 por iniciativa da Escola Nacional de Administração Pública. ${ }^{23}$

A expressão "nível de rua" se refere a servidores que interagem diretamente com os cidadãos na prestação de serviços públicos: professores, policiais, assistentes sociais e profissionais de saúde, entre outros. Segundo a análise de Lipsky, ${ }^{24}$ a complexidade das situações enfrentadas por esses funcionários em seu dia-a-dia, acentuada pela insuficiência de recursos e por diretrizes institucionais imprecisas ou contraditórias, tornaria impossível a execução do trabalho pela aplicação de soluções padronizadas. Em vez disso, suas atividades exigiriam a contínua interpretação das normas e procedimentos prescritos. Esse ambiente de escassez e incerteza daria margem não somente para os burocratas "de nível de rua" agirem conforme sua própria percepção dos objetivos institucionais, mas também de formas que contrariam ou subvertem esses objetivos (Lipsky, [1980] 2010: 163).

A contribuição fundamental de Lipsky foi demonstrar que a discricionariedade dos servidores é um ingrediente constitutivo e inafastável das práticas burocráticas na administração pública. Entretanto, sua análise se reveste de um claro viés normativo ao descrever as dissonâncias entre a formulação e a execução de políticas públicas como uma oposição entre os objetivos organizacionais estabelecidos pelos gestores e as iniciativas de funcionários de níveis hierárquicos mais baixos, que resistiriam ativamente à implementação de mecanismos de avaliação de seu desempenho a fim de preservar sua autonomia (Lipsky, [1980] 2010: 53). ${ }^{25}$

Como indicam Hoag e Hull, etnografias recentes têm expandido as proposições de Lipsky ao demonstrar, por exemplo, que a discricionariedade pode ser necessária para o próprio cumprimento das normas, "uma vez que a norma rigidamente executada poderia estar 'errada' (i.e., em desacordo com o espírito da lei) em certos contextos" (2017:12). No entanto, a despeito de sua firme recusa de uma abordagem instrumental do funcionamento do serviço público, a interrogação proposta pelos autores para o desenvolvimento de futuras pesquisas não deixa de
23| Em 2018, Lipsky havia ministrado palestra na ENAP sobre o papel das burocracias do nível da rua na implementação de políticas públicas. Uma entrevista gravada naquela oportunidade está disponível no site da instituição (https://www.enap. gov.br/index.php/pt/noticias/ enap-entrevista-michaellipsky-fala-sobre-papel-dasburocracias-do-nivel-da-rua).

24 | estudo, realizado nos Estados Unidos, diz respeito às décadas de 1960 e 1970, mas parece possível considerar que essa descrição permanece válida em grande medida, sobretudo com o aprofundamento das políticas neoliberais e a desvalorização acentuada do serviço público nas décadas seguintes.

25 | Embora a ênfase na ação individual esteja presente nos dois casos, a preocupação de Lispky com medidas de controle se afasta da perspectiva preconizada no curso sobre "Ética e Serviço Público", no qual a autonomia dos servidores, desde que exercida com "discernimento", descrita como um ingrediente fundamental para a melhoria do serviço público. Sob esse aspecto, a iniciativa da ENAP de traduzir o estudo de Lipsky pode expressar um deslocamento recente no modo de conceber a relação entre administração pública e servidores. 
se aproximar da ênfase de Lipsky na relativa autonomia de indivíduos em face das demandas de outros indivíduos:

\footnotetext{
A questão que decorre desse insight a respeito da discricionariedade é se os interesses "pessoais" ou predisposições dos burocratas intervêm nas decisões burocráticas. [...] Assim como os cientistas, espera-se que eles desempenhem sua tarefa com objetividade e neutralidade política [...]. Mas não deveria ser uma surpresa que burocratas têm emoções e dilemas morais a respeito de quem deve ser atendido. Em síntese, os burocratas são pessoas e, para além de revelar a inadequação de seus estereótipos, deveríamos aceitar isso como uma premissa básica (Hoag \& Hull, 2017: 13). ${ }^{26}$
}

Embora não se tratasse de atendimento ao público, foi também do cumprimento ponderado das normas que se ocuparam os servidores envolvidos no processo da cafeteira desaparecida. Também não há dúvida de que suas emoções e valores foram decisivos para que o caso tivesse o desfecho que teve. Entretanto, o que a tramitação desse processo evidencia, em contraste tanto com as lições do curso da ENAP quanto com as análises acadêmicas mencionadas, é que a capacidade de conter os efeitos indesejáveis do automatismo das normas e fórmulas não é, nem poderia ser, um atributo individual. O discernimento burocrático - termo que me parece mais adequado tanto por sua presença no universo nativo quanto por evitar conotações negativas da noção de discricionariedade -é, antes, uma qualidade coletivamente produzida e sustentada. Por isso mesmo, não diz respeito a sujeitos, mas a ações que só podem existir com o concurso de diferentes pessoas, assim como de documentos, assinaturas, pareceres, despachos, carimbos e outros artefatos-como aliás testemunha a figura 1 acima, que reproduz a capa do processo da cafeteira desaparecida e as instâncias pelas quais passou.

Ciméa Barbato Bevilaqua é professora titular do Departamento de Antropologia e do Programa de Pós-Graduação em Antropologia e Arqueologia da Universidade Federal do Paraná. É doutora em Antropologia Social pela Universidade de São Paulo (2002) e realizou estágios pós-doutorais na London School of Economics and Political Science (2010) e na Universidade Federal de São Carlos (2016). Atua nas áreas de antropologia do estado e do direito, com ênfase no estudo etnográfico de práticas burocráticas e técnicas jurídicas.

CONTRIBUIÇÃo DE AUTORIA: Não se aplica. 


\section{REFERÊNCIAS BIBLIOCRÁFICAS}

ARETXACA, Begoña. 2003. "Maddening States". Annual Review of Anthropology, 32, 393-410. https://doi.org/10.1146/ annurev.anthro.32.061002.093341.

BARNARD, Alan and SPENCER, Jonathan (eds.). 2010. The Routledge Encyclopedia of Social and Cultural Anthropology. 2nd ed. (1st ed. 1996). London and New York: Routledge.

BEAR, Laura and MATHUR, Nayanika. 2015. "Introduction. Remaking the public good: a new Anthropology of Bureaucracy". The Cambridge Journal of Anthropology, 33(1): 1834. https://doi.org/10.3167/ca.2015.330103

BERNSTEIN, Anya and MERTZ, Elizabeth. 2011. "Introduction. Symposium on Bureaucracy: ethnography of the state in everyday life". PoLAR, 34(1), 6-10. https:// doi.org/10.1111/j.1555-2934.2011.01135.x

\section{BIERSCHENK, Thomas and OLIVIER} DE SARDAN, Jean-Pierre (eds.). 2014. States at work: dynamics of African bureaucracies. Leiden and Boston: Brill.

BRASIL. 2005. Dicionário brasileiro de terminologia arquivística. Rio de Janeiro: Arquivo Nacional. http:// www.arquivonacional.gov.br/images/ pdf/Dicion_Term_Arquiv.pdf.

DAS, Veena and POOLE, Deborah. 2004. "State and its margins: comparative ethnographies". In DAS, Veena and POOLE, Deborah (eds.), Anthropology in the margins of the state. Oxford and New York: Oxford University Press, pp. 3-33.

ENAP. 2014. Módulo 1: Conceitos básicos. Ética e serviço público. Brasília: Escola Nacional de Administração Pública.
FASSIN, Didier (ed.). 2015. At the heart of the state: the moral world of institutions. London: PlutoPress.

FERREIRA, Letícia Carvalho de Mesquita e NADAI, Larissa (orgs.). 2015. "Introdução: Reflexões sobre burocracia e documentos". Apresentação do dossiê Burocracia e Documentos. Confluências 17(3): 7-13. https:// doi.org/10.22409/conflu17i3.p443

FOUCAULT, Michel [1978] 1998. Microfísica do poder. Rio de Janeiro: Craal.

GRAEBER, David. 2012. "Dead zones of imagination: on violence, bureaucracy and interpretive labor". HAU: Journal of Ethnographic Theory, 2(2): 105-128. https://doi.org/10.14318/hau2.2.007

GUPTA, Akhil. [1995] 2006. "Blurred boundaries: the discourse of corruption, the culture of politics, and the imagined state". In SHARMA, Aradhana and GUPTA, Akhil (eds.), The anthropology of the state: a reader. Malden (MA) and Oxford: Blackwell, pp. 211-242.

GUPTA, Akhil. -2012. Red Tape: Bureaucracy, structural violence, and poverty in India. Durham and London: Duke University Press.

HAHONOU, Eric Komlavi and MARTIN, Tomas Max. 2019. "Immersion in the bureaucratic field: methodological pathways" (Introduction to Special Issue). Critique of Anthropology, 39(2): 122-138. https:// doi.org/10.1177/0308275X19842921

HANSEN, Thomas Blom \& STEPPUTAT, Finn. 2001. "Introduction: States of imagination". In HANSEN, Thomas Blom and STEPPUTAT, Finn (eds.), States of imagination: ethnographic explorations of the postcolonial state. Durham and London: Duke University Press, pp. 1-38. 
HERZFELD, Michael. 1992. The social production of indifference. Exploring the symbolic roots of Western Bureaucracy. Chicago: The University of Chicago Press.

HEYMAN, Josiah. 2012. “Deepening the Anthropology of Bureaucracy." Anthropological Quarterly, 85(4): 1269-1277. https://www.jstor.org/stable/41857300

HOAG, Colin \& HULL, Matthew. 2017. "A review of the anthropological literature on the civil service". Policy Research Working Paper 8081. World Bank, Development Research Group, Impact Evaluation Team. http://documents.worldbank.org/curated/ en/492901496250951775/pdf/WPS8081.pdf.

HULL, Matthew. 2012. "Documents and bureaucracy". Annual Review of Anthropology, 41: 251-67. https://doi.org/10.1146/ annurev.anthro.012809.104953

INCOLD, Tim (ed.).1994. Companion Encyclopedia of Anthropology: humanity, culture and social life. 1.ed. London and New York: Routledge.

LEA, Tess. 2012. "When looking for anarchy, look to the state: fantasies of regulation in forcing disorder within the Australian Indigenous estate". Critique of Anthropology, 32(2): 109-124. https:// doi.org/10.1177/0308275X12438251

LIPSKY, Michael. [1980] 2010. "Street-level bureaucracy: dilemmas of the individual in public services" (Edição brasileira: Burocracia de nível de rua: dilemas do indivíduo nos serviços públicos. Brasília: ENAP, 2019. Tradução de Arthur Eduardo Moura da Cunha).

KEANE, Webb. 2016. Ethical life: its natural and social histories. Princeton and Oxford: Princeton University Press.
KUPER, Adam and KUPER, Jessica (eds.). 2004. The Social Science Encyclopedia. 3rd ed. London and New York: Routledge.

LATOUR, Bruno. 2004. "Scientific objects and legal objectivity". In POTTAGE, Alain and MUNDY, Martha (eds.), Law, anthropology, and the constitution of the social. Cambridge: Cambridge University Press, pp. 73-114.

\section{LEWANDOWSKI, Andressa. 2017. O direito} em última instância: uma etnografia no Supremo Tribunal Federal. Rio de Janeiro: Lúmen Juris.

MATHEWS, Andrew S. 2008. "State making, knowledge, and ignorance: translation and concealment in Mexican forestry institutions". American Anthropologist 110(4): 484-494. https:// doi.org/10.1111/j.1548-1433.2008.00080.x

MATHUR, Nayanika. 2017. "Bureaucracy". Cambridge Encyclopedia of Anthropology (Online). https://www.anthroencyclopedia. com/entry/bureaucracy.

MITCHELL, Timothy. [1999] 2006. "Society, economy and the state effect". In SHARMA, Aradhana and GUPTA, Akhil (eds.), The anthropology of the state: a reader. Malden (MA) and Oxford: Blackwell, pp. 169-186.

MUZZOPAPPA, Eva \& VILLALTA, Carla. 2011. "Los documentos como campo: reflexiones teóricometodológicas sobre un enfoque etnográfico de archivos y documentos estatales". Revista Colombiana de Antropología, 47(1): 13-42. https://www.icanh.gov.co/recursos_user/ imagenes//ICANH\%2OPORTAL/ PUBLICACIONES/RCA\%2OVOL.47\%20 No\%201/v47n1a01.pdf

NAKASSIS. Constantine V. et al. 2013. "Book Symposium - Government of paper: the materiality of bureaucracy in urban Pakistan (Matthew Hull)". HAU: Journal of Ethnographic Theory, 3 (3): 399-447. https://www.journals. uchicago.edu/doi/pdfplus/10.14318/hau3.3.022 
PEIRANO, Mariza. 2002. This horrible time of papers: documentos e valores nacionais. Série Antropologia 312. Brasília: Universidade de Brasília / Departamento de Antropologia. http://www.dan.unb.br/images/ doc/Serie312empdf.pdf

PINKER, Annabel. 2015. "Papering over the gaps: documents, infrastructure and political experimentation in Highland Peru". The Cambridge Journal of Anthropology, 33(1): 97-112. https:// doi.org/10.3167/ca.2015.330108

PINTO, Danilo César Souza. 2007. Em nome da segurança - e da desconfiança: um estudo antropológico sobre o funcionamento da burocracia. São Paulo, dissertação de Mestrado, Programa de Pósgraduação em Antropologia Social. Universidade Federal de São Carlos.

SCOTT, James C. 1998. Seeing like a state: how certain schemes to improve the human condition have failed. New Haven and London: Yale University Press.

SELLEN, Abigail ]. and HARPER, Richard H. R. 2002. The myth of the paperless office. Cambridge (MA) and London: The MIT Press.

SHARMA, Aradhana and CUPTA, Akhil. 2006. "Introduction: Rethinking theories of the state in an age of globalization". In SHARMA, Aradhana and CUPTA, Akhil (eds.), The anthropology of the state: a reader. Malden (MA) and Oxford: Blackwell, pp. 1-41.
SOUZA LIMA, Antonio Carlos (org.). 2012. "Dossiê: Fazendo Estado". Revista de Antropologia, 55(2): 559-832. http://www. revistas.usp.br/ra/article/view/59295/64154

SPENCER, Jonathan. 2007. Anthropology, politics, and the state: democracy and violence in South Asia. Cambridge: Cambridge University Press.

TAUSSIG, Michael. 1993. "Maleficium: state fetishism". In APTER, Emily and PIETZ, William (eds.), Fetishism as cultural discourse. Ithaca: Cornell University Press, pp. 217-247.

TEIXEIRA, Carla Costa e SOUZA LIMA, Antonio Carlos de. 2010. "A antropologia da administração e da governança no Brasil: área temática ou ponto de dispersão?" In MARTINS, Carlos Benedito (coord. geral) e DUARTE, Luiz Fernando Dias (coord. de área), Horizontes das Ciências Sociais no Brasil: Antropologia. São Paulo: Anpocs, pp. 51- 95.

VISCARDI, Cláudia M. R. 2018.

"Corporativismo e neocorporativismo". Estudos Históricos 31(64):243-256. http://dx.doi. org/10.1590/S2178-14942018000200007

WEBER, Max. [1946] 1982. "Burocracia". In WEBER, Max, Ensaios de Sociologia (edição e introdução de H.H. Gerth e C. Wright Mills). Rio de Janeiro: LTC, pp. 229-282.

Recebido em 21 de maio de 2020 . Aceito em 22 de setembro de 2020. 